\title{
Neurotrophin Modulation of the Monosynaptic Reflex after Peripheral Nerve Transection
}

\author{
Lorne M. Mendell, ${ }^{1}$ Richard D. Johnson,, ${ }^{2,3}$ John B. Munson ${ }^{3}$ \\ ${ }^{1}$ Department of Neurobiology and Behavior, State University of New York at Stony Brook, Stony Brook, New York 11794 , \\ 2Department of Physiological Sciences, College of Veterinary Medicine, and ${ }^{3}$ Department of Neuroscience, College of \\ Medicine, University of Florida, Gainesville, Florida 32610-0144
}

The effects of neurotrophin-3 (NT-3) and NT-4/5 on the function of axotomized group la afferents and motoneurons comprising the monosynaptic reflex pathway were investigated. The axotomized medial gastrocnemius (MG) nerve was provided with NT-3 or NT-4/5 for 8-35 d via an osmotic minipump attached to its central end at the time of axotomy. After this treatment, monosynaptic EPSPs were recorded intracellularly from MG or lateral gastrocnemius soleus (LGS) motoneurons in response to stimulation of the heteronymous nerve under pentobarbital anesthesia. Controls were preparations with axotomized nerves treated directly with vehicle; other axotomized controls were administered subcutaneous NT-3. Direct NT-3 administration $(60 \mu \mathrm{g} / \mathrm{d})$ not only prevented the decline in EPSP amplitude from axotomized afferents (stimulate MG, record LGS) observed in axotomy controls but, after 5 weeks, led to EPSPs larger than those from intact afferents. These central changes

It is now established that neurotrophin-3 (NT-3) is a prenatal survival factor for muscle spindle and tendon organ afferents that express the high-affinity tyrosine kinase $\mathrm{C}$ (trkC) receptor (HoryLee et al., 1993; Snider and Silos-Santiago, 1996; Wright et al., 1997). In adults, muscle spindles express NT-3 (Copray and Brouwer, 1994), and adult group I muscle afferents continue to express the NT-3 high-affinity receptor trkC (McMahon et al., 1994). Thus, NT-3 might exert a trophic influence on the biophysical properties and synaptic function of spindle afferent fibers. In a brief preliminary communication (Munson et al., 1997a), we reported that continuous application of NT-3 to the proximal end of a muscle nerve axotomized for 5 weeks reversed the decline in EPSP amplitude expected from axotomized spindle afferents (Goldring et al., 1980; for review, see Titmus and Faber, 1990). In fact, the EPSPs in such preparations were larger than those in intact preparations. The first aim of the present work was to determine the mechanisms by which this increase takes place. Thus, we established the time course of this effect as well as its persistence after NT-3 was removed. The behavior of the synapses during high-frequency stimulation $(167 \mathrm{~Hz})$ was investigated as was whether the enhanced central synaptic action could

\footnotetext{
Received Aug. 31, 1998; revised Jan. 28, 1999; accepted Jan. 28, 1999.

This work was supported by National Institutes of Health Grants NS-15913 (Javits Neuroscience Award to J.B.M.) and NS-16996 (Javits Neuroscience Award to L.M.M.). Additional support was furnished by Grants NS-14899 and NS-32264 to L.M.M. We thank Kim Foli and Vicki Dugan for technical support, Dr. Nancy Mendell for statistical consultation, Genentech, San Francisco, CA for provision of

NT-4/5, and Regeneron Pharmaceuticals for provision of NT-3.

Correspondence should be addressed to L. M. Mendell at the above address.

Copyright (C) 1999 Society for Neuroscience $0270-6474 / 99 / 193162-\bullet \$ 05.00 / 0$
}

were paralleled by recovery of group I afferent conduction velocity. Removal of NT-3 4-5 weeks after beginning treatment resulted in a decline of conduction velocity and EPSP amplitude within 1 week to values characteristic of axotomy. The increased synaptic efficacy after NT-3 treatment was associated with enhanced connectivity of single afferents to motoneurons. NT-4/5 induced modest recovery in group I afferent conduction velocity but not of the EPSPs they elicited. NT-3 or NT-4/5 had no effect on the properties of treated motoneurons or their monosynaptic EPSPs. We conclude that NT-3, and to a limited extent NT-4/5, promotes recovery of axotomized group la afferents but not axotomized motoneurons or the synapses on them.

Key words: NT-3; NT-4/5; neurotrophin; motoneuron; motor neuron; muscle spindle; group la fiber; spinal cord; axotomy; EPSP

be associated with increased central connectivity of individual spindle afferents to motoneurons. Finally, we ascertained whether these central changes are associated with alterations in properties of the afferent fibers. For comparison, the effects of directly applied NT-4/5 were determined. NT-3 applied subcutaneously in preparations with an axotomized muscle nerve and vehicle applied directly to the axotomized muscle nerve served as controls.

Application of the neurotrophin to the peripheral nerve also treated axotomized motor axons. Axotomized motoneurons in neonatal and adult rats can be rescued from death at least transiently by application of the trkB ligands NT-4/5 and BDNF (Sendtner et al., 1992; Yan et al., 1992; Schmalbruch and Rosenthal, 1995), and trkB and trkC are expressed on motoneurons (Johnson et al., 1996). This motivated an investigation of whether these neurotrophins could substitute for the periphery in promoting recovery of motoneuron properties as well as their synaptic input from the effects of axotomy.

Some of these data are reported in previous publications (Mendell et al., 1995; Munson et al., 1997a) and portions of the work have been presented in abstract form (Munson et al., 1997b; Mendell et al., 1996, 1998).

\section{MATERIALS AND METHODS}

Experiments were performed in the Department of Neuroscience at the University of Florida in Gainesville in accordance with IACUC procedures. All animals were deeply anesthetized during the surgical and experimental procedures and were killed by anesthetic overdose at the conclusion of the acute experiment.

Preparatory surgery. In 32 cats, we performed an initial surgery using sterile procedures and isoflurane anesthesia. The left medial gastrocnemius (MG) muscle was excised. In 29 cats, the sectioned left MG muscle 


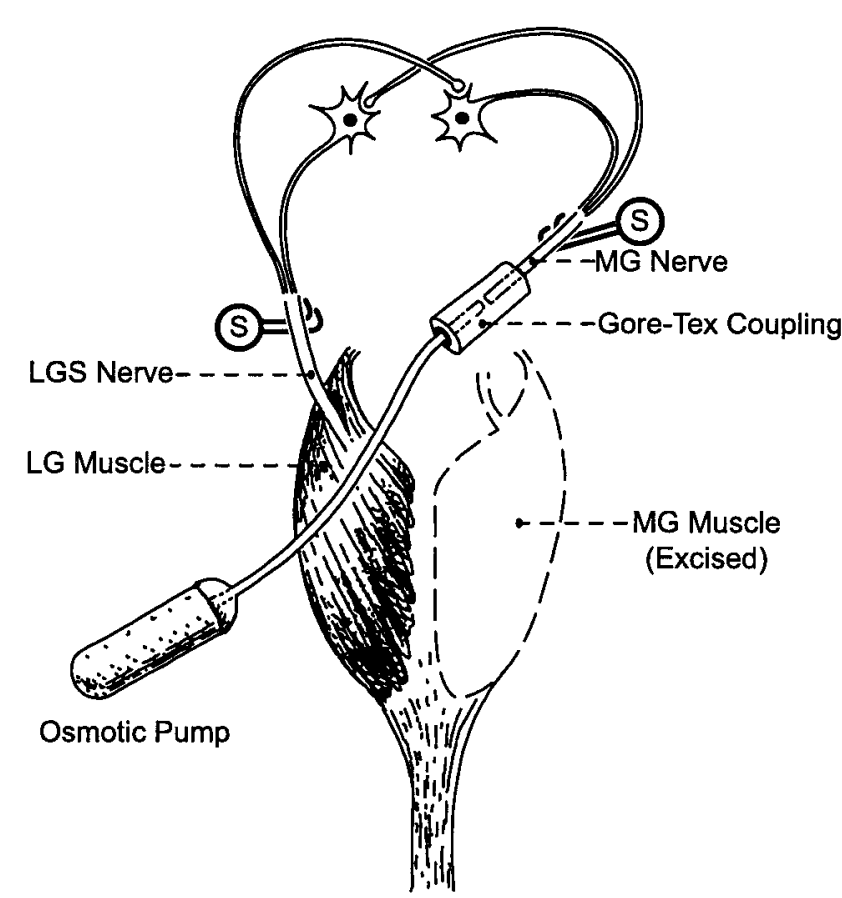

Figure 1. Placement of the minipump and stimulating electrodes on muscle nerves. Recording microelectrode and cord dorsum recording electrode not shown.

nerve was coupled by a Gore-Tex sleeve to a SILASTIC tube and miniosmotic pump (Alzet 2ML2 or 2ML4; Fig. 1) for direct administration of neurotrophin [NT-3 $(n=22)$ or NT-4/5 $(n=3)$ at $60 \mu \mathrm{g} / \mathrm{d}]$ or vehicle $(n=4)$ (Friedman et al., 1995; Munson et al., 1997c). The vehicle was $4.5 \%$ mannitol, $0.5 \%$ sucrose, $10 \mathrm{~mm}$ histidine, pH 5.0. Neurotrophins or vehicle were applied for 1-5 weeks. Gore-Tex was provided by WL Gore \& Associates, Inc., Flagstaff, AZ, NT-3 by Regeneron Pharmaceuticals, Tarrytown, NY, and NT-4/5 by Genentech, San Francisco, CA.

In 9 of the 22 NT-3 cats (persistence experiments), NT-3 was administered as above for 4 or 5 weeks and then withdrawn for 3 or more days before the terminal experiment. In three additional cats, the sectioned left MG nerve was capped with a 10-mm-long blind Gore-Tex sleeve, and the neurotrophin NT-3 was administered subcutaneously by a miniosmotic pump placed between the shoulders (one cat) or on the right hip (two cats). Data from 12 unoperated cats were obtained from previous experiments performed in this laboratory (Mendell et al., 1995; R. D. Johnson and J. B. Munson, unpublished observations).

Experimental procedures. For terminal acute experiments, deep surgical anesthesia was induced intraperitoneally and maintained intravenously with pentobarbital sodium ( $40 \mathrm{mg} / \mathrm{kg}$ initial dose) to achieve areflexia. Body temperature was maintained near $37^{\circ} \mathrm{C}$; respiration and heart rate were monitored with an end-expired $\mathrm{pCO}_{2}$ monitor and esophageal stethoscope, respectively. The L5-S2 spinal cord segments were exposed by dorsal laminectomy, the left popliteal fossa was opened, and mineral oil pools were formed over each. The MG and lateral gastrocnemius soleus (LGS) nerves were placed on platinum stimulating electrodes (Fig. 1). The intact LGS nerve was crushed distal to the stimulating electrodes. In all cases, we recorded from heteronymous motoneurons to permit examination of the effects of treating afferent fibers and motoneurons independently. Thus, after treatment of the MG nerve, stimulating the axotomized MG nerve and recording from intact LGS motoneurons would isolate the findings to those produced on the afferent fibers and their central connections. Similarly, stimulating the intact LGS nerve and recording from axotomized MG motoneurons would isolate the findings to those produced on the motoneurons.

Cord dorsum recording. The cord dorsum potential (CDP) was recorded with a silver ball electrode positioned on the spinal cord dorsum near the L7-S1 border. CDPs (averages of 16 at $1 \mathrm{~Hz}$ ) were elicited by $2 \times, 3 \times, 5 \times$ and $10 \times$ threshold electrical stimulation of the MG and LGS nerves at identical distances from the cord dorsum recording site.
Records were digitized, permitting measurement at $50 \mu \mathrm{sec}$ intervals, and stored for later analysis.

Motoneuron properties and EPSPs. Intracellular recordings to obtain electrical properties (conduction velocity, input resistance, afterhyperpolarization, rheobase) from MG and LGS motoneurons used procedures described previously (Zengel et al., 1985). EPSPs (averages of $8-32$ ) were recorded in motoneurons having action potentials $>60 \mathrm{mV}$, using micropipette electrodes filled with $3 \mathrm{M} \mathrm{KCl}$. Shocks to the heteronymous nerve at 3 times threshold were delivered at $0.5 \mathrm{~Hz}$ or in trains of 32 shocks at $167 \mathrm{~Hz}$ every $2 \mathrm{sec}$, with the resultant 32 EPSPs averaged in register (Collins et al., 1984). This permitted measurement of progressive changes in EPSP amplitude during high-frequency stimulation, either increases or decreases. This is referred to as EPSP amplitude modulation $=100 *\left[\left(\mathrm{EPSP}_{30}+\mathrm{EPSP}_{31}\right) / 2 /\left(\mathrm{EPSP}_{1}\right)\right]$. Modulation is $>0$ if EPSP amplitude increases during the burst and $<0$ if it decreases. Extracellular field potentials were subtracted electronically from the intracellular records.

Single-fiber stimulation. This was accomplished in two different ways. In three preparations, we used the spike-triggered averaging method (Mendell and Henneman, 1971). In these cases, single dorsal root filaments were dissected in continuity and placed on recording electrodes. The limb was completely denervated to minimize activity from afferents innervating structures other than the MG muscle. The tube used to deliver the NT-3 was cut a few centimeters from the end of the axotomized MG nerve, and a suture was tied to it. When this was stretched or pushed down gently, afferent activity could be recorded. This was used to trigger the averaging computer that was configured to average the intracellular potential from an impaled motoneuron. Care had to be taken to not stretch the nerve for too long a time because the axotomized afferent would begin discharging at a very high frequency (Johnson and Munson, 1991), thereby decreasing EPSP amplitude (Honig et al., 1983). However, this was difficult to prevent completely in most cases. Typically, averages of 256-512 sweeps were taken in these experiments. Single-fiber EPSPs did not exhibit compound shapes, as might have been anticipated if multiple afferent fibers discharged in synchrony in response to manipulation of the cuff. In a fourth experiment, we found two well isolated spindle afferents in a single filament. All L6, L7, and S1 rootlets except this small filament were cut. The MG nerve was stimulated electrically (Mendell and Henneman, 1971), and the EPSPs were measured in response to the low-threshold afferent. The response to stimulation of both afferent fibers was then obtained with the response to the highthreshold afferent being derived by electronic subtraction of the two records.

Statistics. Statistical analysis consisted of ANOVA (one-way, two-way, nested ANOVA, or analysis of covariance depending on the hypothesis being tested) to evaluate time and/or treatment effects. When significant, these were followed by pair-wise comparison of treatment means using the Student-Newman-Keuls test that adjusts for multiple comparisons. In all cases, the mean values from individual animals were considered as the unit of observation to minimize bias because of interanimal variability in EPSP amplitude, motoneuron properties, etc.

\section{RESULTS}

\section{NT-3 effects on afferent conduction velocity}

When a peripheral nerve is cut, the conduction velocity of the afferent fibers diminishes over several weeks (Collins et al., 1986). We determined whether providing NT-3 to the cut MG nerve had any effect on the decrease in conduction velocity. In each preparation, the afferent volley was measured on the cord dorsum in response to stimulation of the intact LGS nerve and the cut MG nerve in the popliteal fossa (one measurement in each preparation). The conduction distances were identical for both. The latency to zero crossing of the compound action potential at $5 \times$ threshold was measured for each (Fig. 2, insets) and expressed as a ratio (Fig. 2). The zero crossing (arrow) occurs at the peak of the compound action potential (Munson and Sypert, 1979a), and so this represents a value of latency greater than that measured at the onset of the compound action potential recorded in a monopolar configuration. Nonetheless, it is important to note that the conduction velocity of these components was in the group I range $(>72 \mathrm{~m} / \mathrm{sec})$. 
Figure 2. Plot of zero crossing ratio versus days after the nerve is axotomized and treatment is begun. Treatment consists of either NT-3 delivered directly to the axotomized nerve (NT-3 direct), vehicle delivered to the axotomized nerve (vehicle direct), or NT-3 delivered subcutaneously (NT-3 subcutaneous). Each point refers to a different preparation and is the ratio of the latency of the zero crossing (inset, arrow) of the afferent volleys elicited by stimulation of the LGS nerve (numerator) and the MG nerve (denominator). Inset illustrates afferent volleys from intact MG and LGS nerves after axotomy of MG and after treatment of axotomized MG with NT-3. As the axotomized MG nerve volley becomes slower, the ratio of its zero crossing time to that of the intact LGS nerve declines from a control value of 1.0. (2) represents two overlapping points.

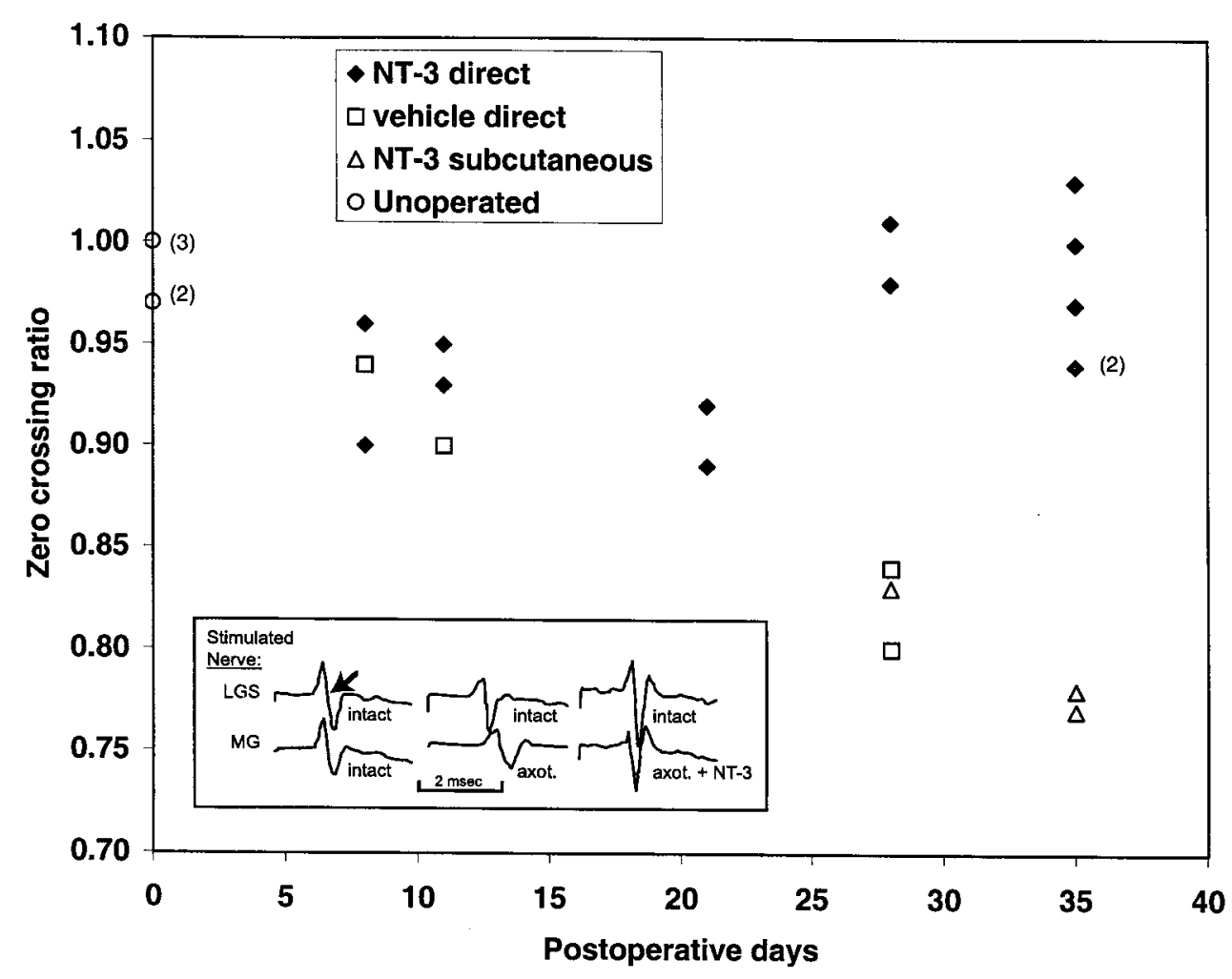

In intact animals, the ratio of zero crossing latencies (LGS: $\mathrm{MG})$ is $\sim 1.0$. After axotomy of the MG nerve with vehicle treatment, the latency of the MG volley increased (because of reduced conduction velocity of its Ia fibers) so that the ratio of the latency of the LGS nerve volley (which was quite constant because the conduction velocity of its group Ia fibers did not change) to the MG nerve volley decreased to $\sim 0.9$ by $10 \mathrm{~d}$, and to $\sim 0.8$ by 4 weeks. After similar treatment of the nerve with NT-3 for 1-5 weeks, the LGS:MG afferent conduction velocity ratio fell less during the initial 2 weeks, reaching a minimum of $\sim 0.9$ at 3 weeks, and then recovered so that the ratio returned to normal values (1.0) by 5 weeks. Systemic treatment with NT-3 via subcutaneous minipump application had no detectable effect on the decrease in afferent conduction velocity.

To ascertain which of the findings were statistically significant, an analysis of covariance was performed that revealed that the slope of the zero crossing versus time relationship differed among the three treatments $\left(F_{(2,13)}=7.15 ; p=0.008\right)$. Subsequent ANOVA revealed no difference in zero crossing ratio between treatment with vehicle and subcutaneous NT-3 $(p>0.05)$, and so these two groups were amalgamated. A two-way ANOVA was then performed considering time ( 8 and $11 \mathrm{~d}$ vs 28 and $35 \mathrm{~d}$ ) and treatment groups (vehicle and subcutaneous NT-3 vs direct NT-3) as factors. A significant interaction between time and treatment group was revealed $\left(F_{(1,13)}=23.20 ; p=0.0003\right)$, as was a significant effect of treatment on zero crossing ratio $\left(F_{(1,13)}=\right.$ 32.44; $p=0.0001)$.

Thus, the change in zero crossing ratio in going from early ( 8 and $11 \mathrm{~d})$ to late $(28$ and $35 \mathrm{~d})$ postoperative times differs for these two groups. Further investigation of this effect by comparing the means indicated that the vehicle-and-subcutaneous NT-3 zero crossing ratio decreased as time increased $(p=0.0009)$, whereas after direct NT-3 application, the zero crossing ratio increased $(p=0.03)$. There was no difference in the zero crossing ratios at 8 and $11 \mathrm{~d}(p=0.6)$, whereas at $28 \mathrm{~d}$ there was a significant difference with NT-3 producing a higher value of zero crossing ratio $(p=0.0001)$.

\section{NT-3 effects on EPSP amplitude from axotomized afferents $(\mathbf{M G} \rightarrow$ LGS)}

An overview of this effect is illustrated in the cumulative sum histograms of EPSP amplitude over all connections at different time points (Fig. 3). The largest EPSPs were substantially bigger after NT-3 treatment than in controls; those in vehicle-treated preparations were substantially smaller. These cusums also illustrate the increase in EPSP amplitude over the NT-3 treatment periods from 1 to 5 weeks. The cusums at 3 and at 4 weeks were virtually identical, although it is clear from both this figure as well as from Figure 4 that EPSP amplitude was slightly larger at 3 weeks than at 4 weeks. We attribute this to sampling and to the normal interanimal variability in EPSP amplitude as observed in controls (see Fig. 4 at 0 postoperative days; also see Discussion).

One problem in evaluating the significance of these changes in EPSP amplitude is that there is considerable variability in mean EPSP amplitude from animal to animal, even in controls. This is seen in Figure 4, in which each point represents the mean EPSP amplitude from a single preparation. On the abscissa is time after axotomy, and on the ordinate is mean amplitude of the EPSPs ( \pm SD) elicited in LGS motoneurons as a result of maximal group Ia stimulation of the MG nerve in that experiment. Values in intact preparations average $2.0 \mathrm{mV}$ (Mendell et al., 1995), and the range in the mean EPSP in six such experiments is illustrated by the open circles on the ordinate. After axotomy it can be seen qualitatively that EPSP amplitude was smaller in preparations treated with vehicle or subcutaneously with NT-3 than after direct administration of NT-3. To examine these changes more quantitatively, we performed a nested ANOVA on the EPSPs and detected a significant difference in EPSP amplitude between 


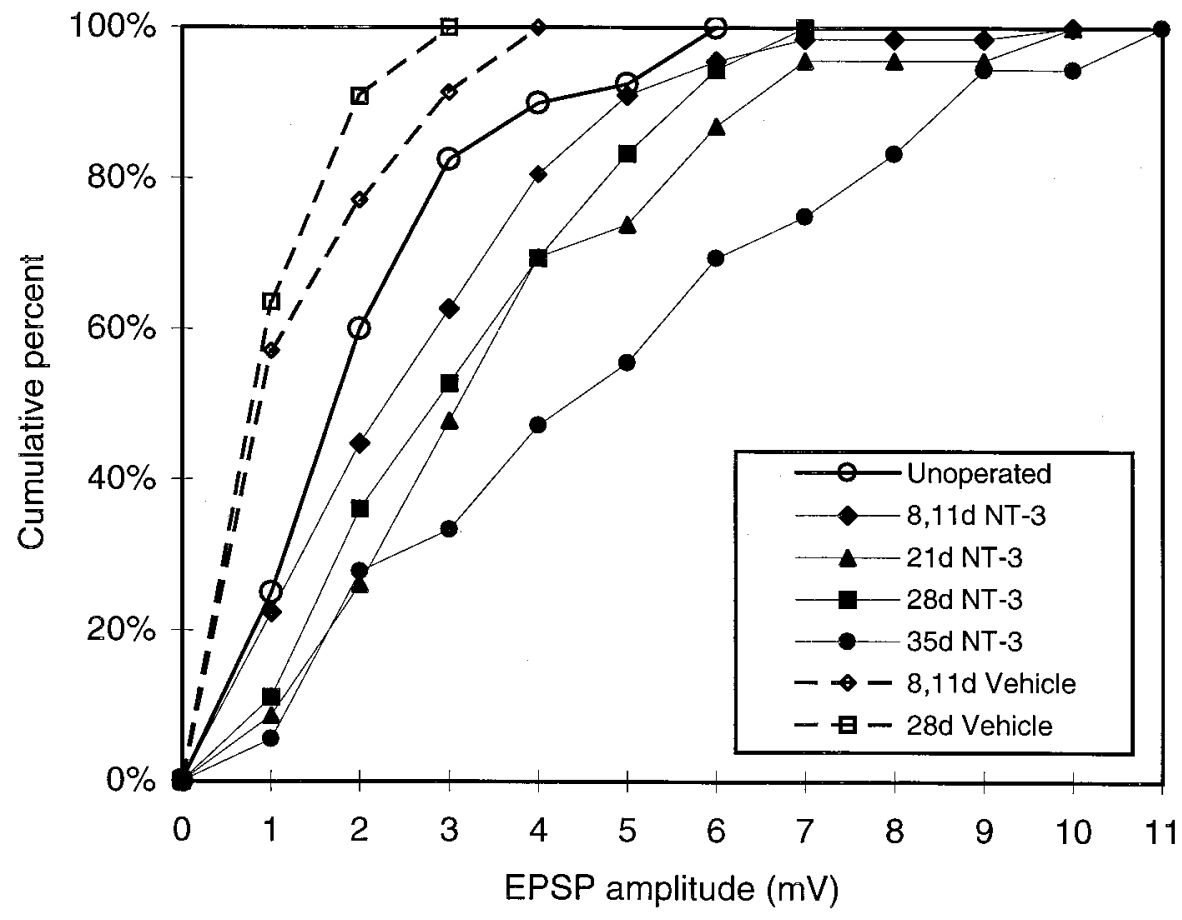

Figure 3. Cumulative amplitude histograms (cusums) for unoperated control preparations (Mendell et al., 1995) and preparations whose MG nerve is axotomized and treated either with NT-3 or vehicle, all for the period listed in the inset, i.e., axotomy and treatment began at the same time and ended at the time of the terminal experiment. The ordinate represents the percentage of EPSP amplitudes in each group smaller than the corresponding value of the abscissa. Note the decrease in EPSP amplitude for vehicle-treated preparations (shift of cusums to the left) and the increase for NT-3-treated preparations (shift of cusums to the right). Note particularly that long duration treatments with NT-3 result in a population of unusually large EPSPs $(>6.0 \mathrm{mV})$, i.e., larger than any observed in control preparations. Note also the small number of EPSPs $<1 \mathrm{mV}$ in NT-3treated animals compared with vehicle-treated animals.

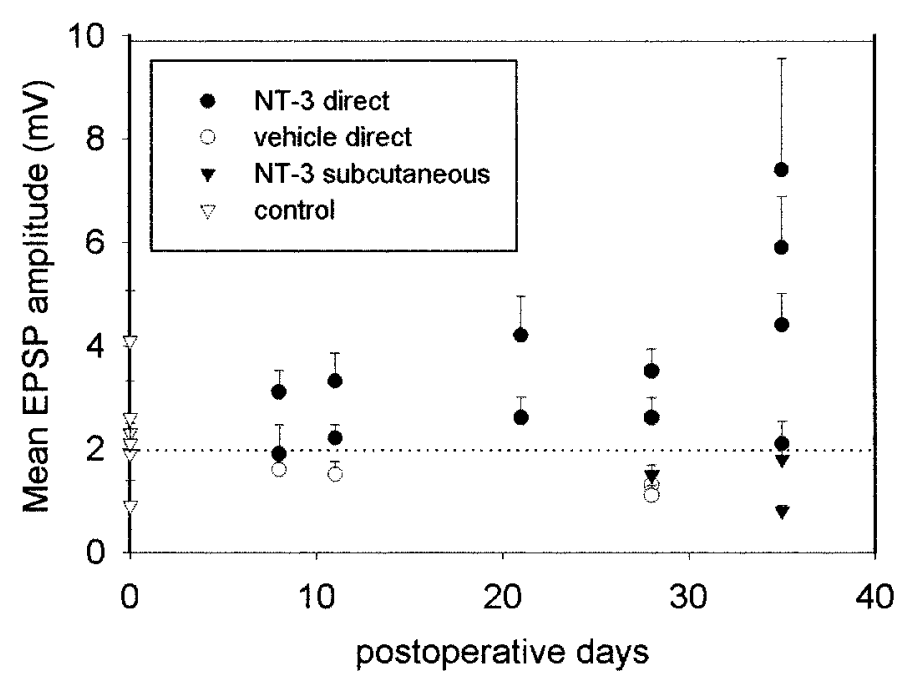

Figure 4. Plot of mean EPSP amplitude elicited by stimulation of the MG nerve in each preparation as a function of days after axotomy and beginning of treatment (as in Fig. 2). Each point refers to a different preparation. NT-3 direct, 12 cats, average of 13 motoneurons per cat (range, 3-22); controls (vehicle-direct and NT-3 subcutaneous), seven cats, average of 16 motoneurons per cat (range, 9-19). A series of values at 0 postoperative days are from unoperated control animals ( 6 cats, average of 6 motoneurons per cat; range, 4-13) (Mendell et al., 1995).

individual animals $\left(F_{(21,277)}=37.2 ; p=0.008\right)$. The nested ANOVA also revealed a significant effect of NT-3 treatment on EPSP amplitude over and above the variability contributed by the individual animals $\left(F_{(3,21)}=6.23 ; p=0.005\right)$. Subsequent analysis of the animal means for each treatment using a StudentNewman-Keuls test at the $p=0.05$ level showed that direct NT-3 treatment resulted in significantly larger mean values of amplitude compared with vehicle treatment or subcutaneous NT-3 treatment, which were not different from each other $(p>0.05)$. This analysis also revealed that direct NT-3 treatment yielded significantly larger $(p<0.05)$ EPSP amplitudes than those in unoperated controls.

In addition, the effect of postoperative time on amplitude was evaluated for direct NT-3 treatment and for combined vehicle direct and subcutaneous NT-3 treated preparations. Controls were not included in this analysis. Analysis of covariance revealed no time-by-treatment interaction $\left(F_{(1,15)}=2.5 ; p=0.13\right)$, indicating no difference in the slopes of amplitude versus postoperative time for the two treatment groups. It also showed no time effect for the combined data $\left(F_{(1,16)}=3.5 ; p=0.08\right)$. Together, these results show that there is no significant correlation between EPSP amplitude and time for either group.

In Figure 5, EPSP amplitude is plotted as a function of afferent conduction latency ratio (as in Fig. 2). The power function fit to these points (least squares, drawn only in Fig. 6) had a correlation coefficient of $0.75(p<0.01)$. This relationship demonstrates that mean EPSP amplitude is correlated with group I afferent conduction velocity over a broad range of treatments and treatment times.

\section{Removal of NT-3}

Six animals were treated with NT-3 for 4 weeks, and the pump was then removed for 3 or $5 \mathrm{~d}(n=3$ for each) before the terminal experiment to test for persistence of the NT-3 effect. Three additional animals were treated for 5 weeks, and the pump was removed for 6,13 , or $22 \mathrm{~d}$. In two of the three " $3 \mathrm{~d}$ off" experiments, EPSP amplitude and afferent conduction velocity remained elevated for $3 \mathrm{~d}$ after NT-3 treatment was discontinued. In only one of four experiments in which treatment was discontinued for 5-6 d did EPSP amplitude and conduction velocity remain elevated. In all the other experiments, EPSP amplitude declined toward normal values $(2.0 \mathrm{mV})$ (Fig. 6). Thus, the effect of NT-3 persisted only 3-6 d after the pump was removed. This graph also reveals that when NT-3 was removed and the effect did not persist, both EPSP amplitude and afferent conduction velocity declined together. The superposition of the points from Figure 5 and the power function fit to those points demonstrates that 


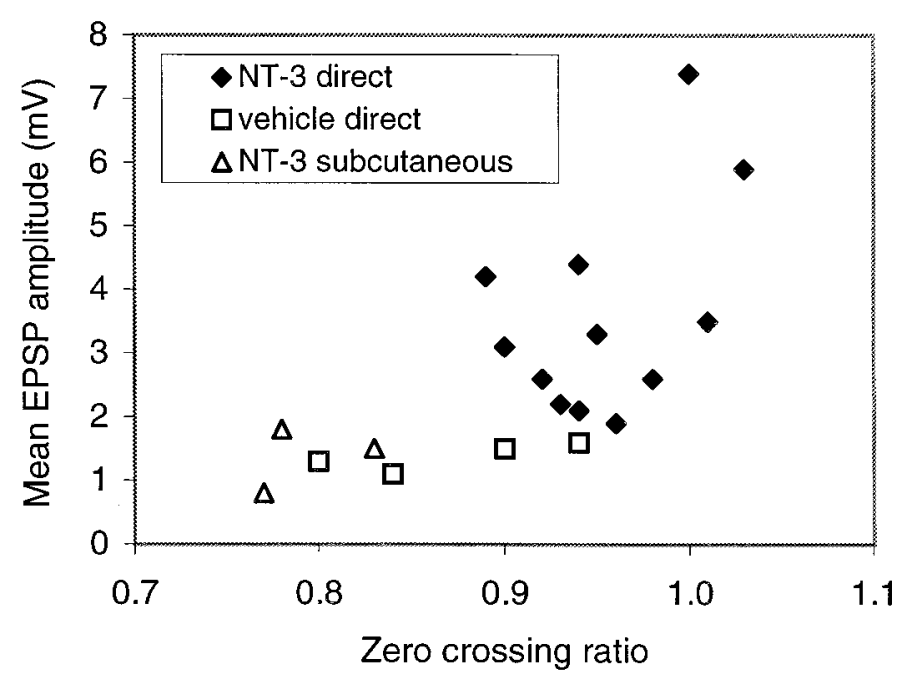

Figure 5. Plot of mean EPSP amplitude versus zero crossing ratio for all the data in Figures 2 and 3 demonstrating that they are related across multiple treatment types and treatment times. Each point refers to a different preparation. These points were fit with an exponential function $y=0.0134 \mathrm{e}^{0.0567 \mathrm{x}}$ with a correlation coefficient of $0.75(p<0.01)$. This regression line is plotted in Figure 6.

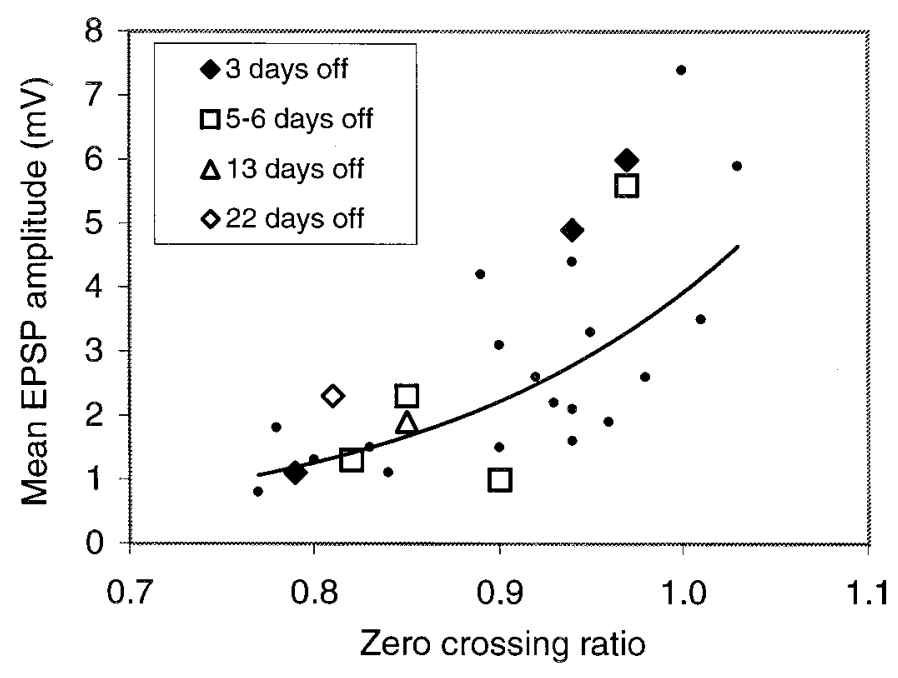

Figure 6. Plot of mean EPSP amplitude versus zero crossing ratio for the nine experiments in which NT-3 was removed after 4-5 weeks. Each point refers to a different preparation. Duration of NT-3 withdrawal before the terminal experiment is given in the legend. Average of 16 motoneurons per cat (range, 8-21). The small dots are data points from the experiments displayed in Figure 5. The regression line is the exponential fit to the points in Figure 5. This plot demonstrates that after removal of NT-3 afferent conduction velocity and mean EPSP amplitude returned to values characteristic of preparations with vehicle or subcutaneous NT-3 treatment.

afferent conduction velocity and mean EPSP amplitude declined to values similar to those produced in the absence of directly applied NT-3, i.e., by axotomized afferents treated directly with vehicle or subcutaneously with NT-3.

\section{Analysis of single-fiber EPSPs in NT-3-treated cats}

In four cats whose axotomized MG nerve was treated with NT-3 (one for 4 weeks; two for 5 weeks; one for 5 weeks with subsequent removal for $22 \mathrm{~d}$ ) the EPSPs produced by single MG Ia afferents were recorded in untreated LGS motoneurons to assess
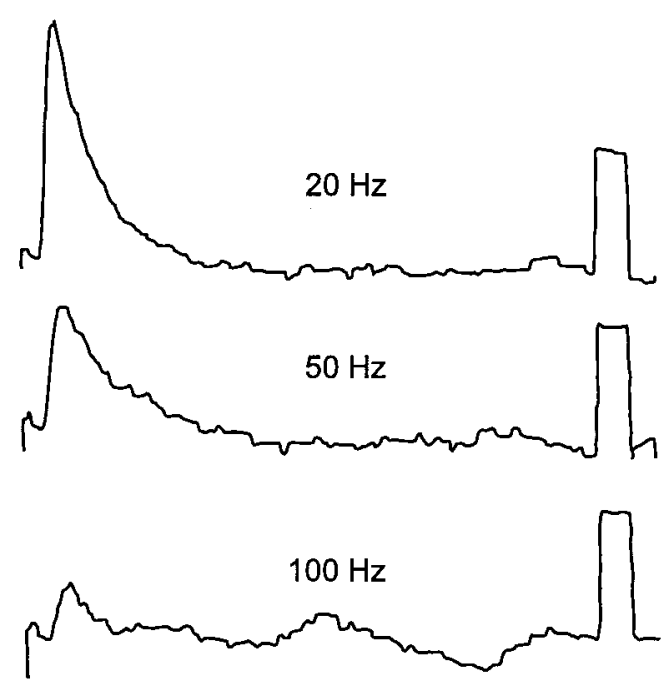

Figure 7. Single-fiber EPSPs produced in an LGS motoneuron using the spike-triggered averaging method. The axotomized $\mathrm{MG}$ nerve was treated with NT-3 for 4 weeks. Three different records are shown, obtained during afferent discharges of different approximate frequencies. Note that during the high-frequency after-discharge, the EPSP is considerably smaller than that elicited during lower frequency discharges of the afferent fiber. Calibration pulse at the end of each trace is $100 \mu \mathrm{V}, 1 \mathrm{msec}$.

afferent connectivity to the motoneuron pool. In three of these cats, spike-triggered averaging was used with the afferents activated by stretching the cuff. In the fourth preparation, all dorsal roots were cut except for a single rootlet shown to have only two group Ia afferents conducting into the spinal cord from the MG nerve; the MG nerve was stimulated electrically (see Materials and Methods). The connectivity between MG Ia afferents and the heteronymous LGS motoneuron pool (i.e., the percentage of LGS motoneurons in which a given MG afferent generates an EPSP) is $\sim 60 \%$ in intact preparations (Scott and Mendell, 1976; Munson and Sypert, 1979b). After axotomy and NT-3 administration, the connectivity values were $83 \%$ (12 connections studied), $85 \%$ (20), $57 \%$ (7), and $100 \%$ (11) (mean connectivity of $84 \%$ in a total of 50 individual heteronymous Ia/motoneuron connections studied). In the cat treated for 5 weeks with subsequent removal for $22 \mathrm{~d}$, connectivity remained high at $95 \%$ (20). Thus, the central connectivity of the NT-3-treated axotomized afferents was substantially elevated above normal values.

The mean amplitude of the single-fiber EPSPs was $63 \mu \mathrm{V}$, similar to values obtained in intact preparations with spiketriggered averaging (65 $\mu \mathrm{V}$; Scott and Mendell, 1976; Munson and Sypert, 1979b). However, because stretching the cuff often resulted in a much higher afferent discharge frequency (up to 200 $\mathrm{Hz}$ ) than in response to muscle stretch in intact preparations $(\sim 20 \mathrm{~Hz})$, it is likely that this measure of amplitude is not comparable to those obtained in earlier experiments. In some cases we were able to determine by direct measurement at a given connection under three different stimulation conditions (Fig. 7, 20, 50, and $100 \mathrm{~Hz}$ ) that the amplitude measured at high frequency could be reduced to $\sim 50 \%$ of that obtained at low frequency. Thus, under similar conditions to those in previous experiments the EPSP amplitude might have been as much as $100 \%$ higher, i.e., closer to $130 \mu \mathrm{V}$, which is twice that observed normally. The preparation studied $22 \mathrm{~d}$ after NT-3 removal had the smallest mean EPSP single-fiber amplitude $(53 \mu \mathrm{V})$. 

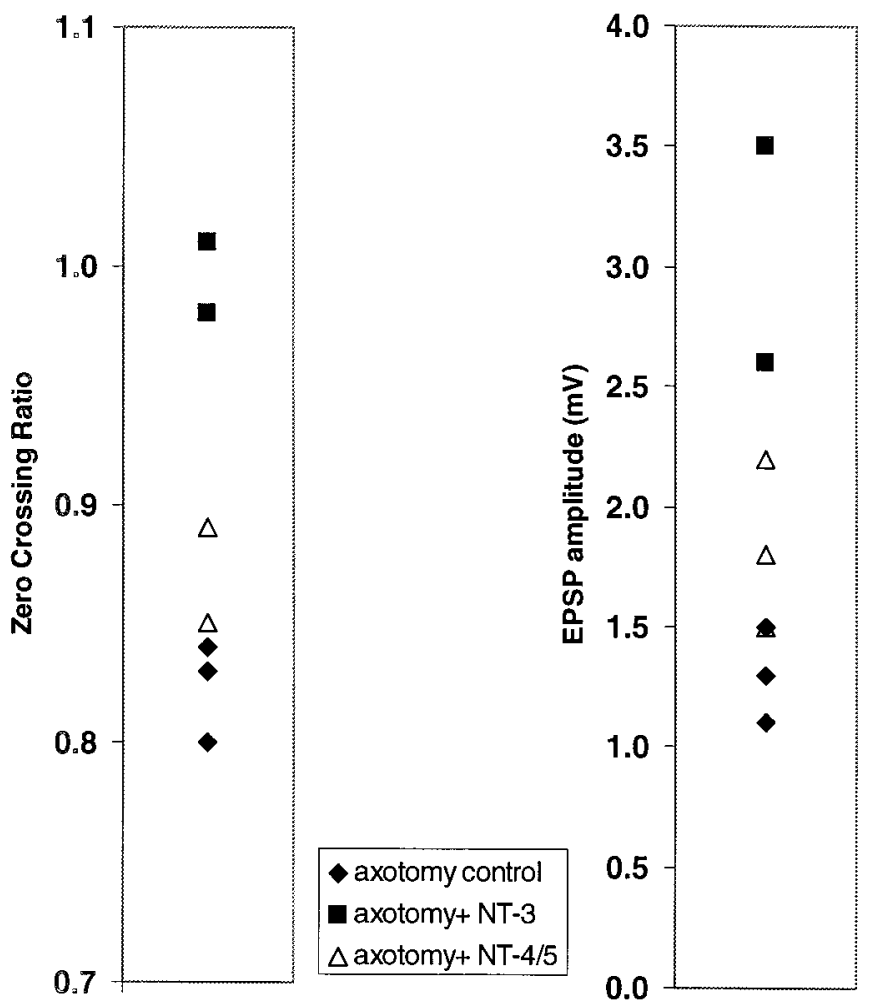

\section{Comparison of effects of NT-3 and NT-4/5 on axotomized muscle spindle afferent fibers and their synaptic connections (MG $\rightarrow$ LGS)}

In three cats we examined the effects of a 4 week application of NT-4/5 to the axotomized MG nerve. We compared the results of this treatment to those obtained over the same 4 week period in axotomized nerves treated either directly with NT-3 or with vehicle applied to the nerve or systemic NT-3 (i.e., axotomized controls). The results for zero crossing ratio, mean EPSP amplitude, and mean values of EPSP amplitude modulation for the individual experiments treated in these three ways are displayed in Figure 8. The zero crossing ratios were smallest from nerves not treated directly with neurotrophin, largest from NT-3-treated nerves, and intermediate for NT-4/5-treated nerves. The zero crossing values for both NT-3 $(n=2)$ and NT-4/5 $(n=3)$ differed significantly from control axotomy values $(n=3)$ after 4 weeks of treatment (one-way ANOVA, $F_{(2,5)}=37.5$; post hoc StudentNewman-Keuls, $p<0.01, p<0.05$, respectively). A similar finding was made for EPSP amplitude (ANOVA, $F_{(2,5)}=12.7$; $p=0.01)$; however the mean amplitude of EPSPs after direct NT-3 treatment differed from control values $(p<0.01)$, but the mean value for NT-4/5 did not. Values for modulation did not differ among the three groups $\left(F_{(2,4)}=0.41 ; p=0.69\right)$. Thus, it is apparent that NT-4/5 may have had some effect on recovery from axotomy that was not as potent as that of NT-3, but the amount of data available does not permit reliable conclusions.

\section{Effects of NT-3 and NT-4/5 on EPSP amplitude and amplitude modulation in axotomized motoneurons (LGS $\rightarrow$ MG)}

Both NT-3 and NT-4/5 had little measurable effect compared with vehicle treatment on either EPSP amplitude or EPSP amplitude modulation produced by intact, untreated LGS afferents in MG motoneurons whose axons had been transected 4-5 weeks

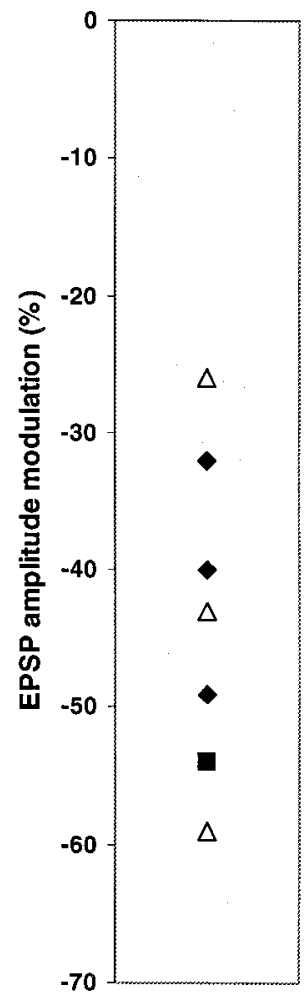

Figure 8. Comparison of effects on axotomized group Ia afferents of 4 weeks direct treatment with NT-3 (average of 17 motoneurons per cat; range, 14-21), with NT-4/5 (average of 5 motoneurons per cat; range, 3-9), or with control treatments (vehicle direct, NT-3 subcutaneous, 14 motoneurons per cat; range, 9-18). Zero crossing data show that NT-3, and to a lesser extent NT-4/5, rescues afferent conduction velocity. Amplitudes of EPSPs elicited by NT-3-treated (but not NT-4/5treated) afferents are significantly larger than those elicited in control experiments. EPSP modulation does not differ among the treatment groups. See Results for statistical details. Axotomy control in legend refers to axotomized afferents treated for 4 weeks with vehicle or with NT-3 delivered subcutaneously.

previously (Table 1). In both cases, one-way ANOVAs on means obtained in each animal revealed no significant differences among the three axotomized treatment groups: treated directly with vehicle or NT-3 subcutaneously, treated directly with NT-3, or treated with NT-4/5. For mean EPSP amplitude in each animal, ANOVA yielded $F_{(2,7)}=1.3, p=0.33$; for mean modulation, $F_{(2,6)}=0.42 ; p=0.67$. This nonsignificant effect on synapses in NT-3-treated motoneurons contrasts with the substantial one that NT-3 elicited on the EPSPs produced by the group Ia afferents that were treated simultaneously in the same preparations (see above).

\section{Effects of NT-3 and NT-4/5 on the properties of axotomized motoneurons}

Axotomy is known to alter the properties of motoneurons (Mendell et al., 1995). Because trkB and trkC are both expressed on most motoneurons (Johnson et al., 1996), it was of interest to examine the effects of NT-3 and NT-4/5 treatments on the properties of axotomized motoneurons. Mean values of rheobase, input resistance, axonal conduction velocity, and afterhyperpolarization (AHP) half decay time over all experiments with numbers of experiments and cells are displayed in Table 1, in which it can be seen that the neurotrophins had little effect on values of these parameters compared with values after axotomy (row 2). ANOVA of the means of these parameters in individual experiments revealed no significant differences; rheobase, $F_{(2,9)}=$ $0.53, p=0.60$; input resistance, $F_{(2,9)}=0.54, p=0.60$; conduction velocity, $F_{(2,9)}=0.38, p=0.69 ; \mathrm{AHP}, F_{(2,9)}=0.37, p=0.70$. These negative results must be viewed in the context of the strong effects that NT-3 had, particularly on afferent conduction velocity and on EPSP amplitude from afferents treated within the same nerve in the same preparation. 
Table 1. Effects of NT-3 and NT-4/5 on axotomized motoneurons

\begin{tabular}{|c|c|c|c|c|c|c|}
\hline & $\begin{array}{l}\text { Conduction } \\
\text { velocity }(\mathrm{m} / \mathrm{s})\end{array}$ & Rheobase (nA) & $\begin{array}{l}\text { Input } \\
\text { resistance }(\mathrm{M} \Omega)\end{array}$ & $\begin{array}{l}\text { AHP half decay } \\
(\mathrm{ms})\end{array}$ & $\begin{array}{l}\text { EPSP amplitude } \\
(\mathrm{LGS} \rightarrow \mathrm{MG}) \\
(\mathrm{mV})\end{array}$ & $\%$ Modulation \\
\hline Unoperated controls & $94 \pm 9(n=60)$ & $15 \pm 8(n=60)$ & $1.1 \pm 0.7(n=58)$ & $22 \pm 10(n=58)$ & $2.0 \pm 1.3(n=55)$ & $-6 \pm 32(n=55)$ \\
\hline $\begin{array}{c}4 \text { wk Vehicle or } \\
\text { NT-3 subQ }\end{array}$ & $69 \pm 9(n=41)$ & $5 \pm 2(n=41)$ & $2.0 \pm 0.5(n=39)$ & $28 \pm 5(n=40)$ & $1.7 \pm 0.9(n=41)$ & $-35 \pm 15(n=41)$ \\
\hline $4-5$ wk NT-3 & $68 \pm 8(n=43)$ & $5 \pm 3(n=29)$ & $1.8 \pm 0.6(n=38)$ & $28 \pm 6(n=37)$ & $1.6 \pm 0.7(n=28)$ & $-41 \pm 16(n=28)$ \\
\hline 4 wk NT-4/5 & $70 \pm 8(n=57)$ & $5 \pm 2(n=58)$ & $2.0 \pm 0.7(n=58)$ & $29 \pm 7(n=58)$ & $1.8 \pm 0.9(n=52)$ & $-31 \pm 25(n=55)$ \\
\hline
\end{tabular}

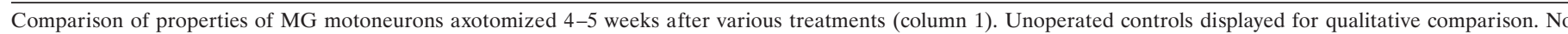

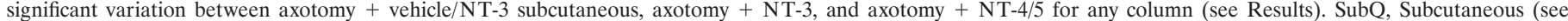

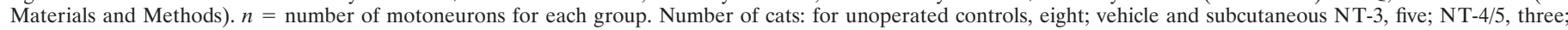
NT-3, four for columns 2-5; three for columns 6 and 7.

\section{DISCUSSION}

Provision of NT-3 (but not NT-4/5) to axotomized group Ia afferents constituting the afferent limb of the monosynaptic reflex pathway in adult cats exerted a major effect on the EPSPs made by the treated fibers onto intact motoneurons. Not only did NT-3 prevent the long-term decrease in EPSP amplitude characteristic of axotomized afferents, but it produced a significant increase in EPSP amplitude compared with intact controls. This suggests that $\mathrm{Ia} /$ motoneuron connections do not normally operate at full capacity. Intact preparations display interanimal variability in mean EPSP amplitudes (Fig. 4). This is generally attributed to sampling, differences in depth of anesthesia, levels of tonic presynaptic inhibition, etc. The present data raise the possibility that differences in muscle NT-3 expression could account for some of the variability.

Both NT-3 and NT-4/5 were found also to restore the conduction velocity of axotomized group I afferent fibers (NT-3 > $\mathrm{NT}-4 / 5)$. The presence of high-affinity trkC receptors on spindle afferent fibers (see introductory remarks) provides a basis for the action of NT-3 on treated axotomized Ia afferent fibers as was found also in the adult rat (Munson et al., 1997c). They confirm the beneficial effects of NT-3 in restoring the function of large diameter muscle afferents, as demonstrated by Gao et al. (1995) after cisplatin-induced peripheral neuropathy and by Helgren et al. (1997) after pyridoxine treatment. The finding that NT-4/5treated afferents had a higher conduction velocity than vehicletreated ones indicates that these afferents may also express trkB receptors, as in the rat (McMahon et al., 1994). However, Munson et al. (1997c) failed to find an effect of NT-4/5 on conduction velocity of group I fibers in the rat.

The expression of trkB in motoneurons (at least in rat) would predict an action for NT-4/5 on axotomized motoneurons. This was not detected, although in the rat NT-4/5 influences both motor axon conduction velocity (Munson et al., 1997c) and cholineacetyltransferase (Friedman et al., 1995). The inability of NT-3 to affect treated axotomized motoneurons suggests either that trkC receptors present on these cells (Johnson et al., 1996) were too few in number to exert a measurable effect or that the actions are different from those measured in these experiments. Other possible reasons for the discrepancies between cat and rat data for sensory and motor neurons include differences in required neurotrophin dosage, treatment duration, involvement of p75 receptors (Chao and Hempstead, 1995), or nonspecific activation of high-affinity receptors.

The finding that NT-3 applied directly to the nerve had consistent effects, whereas subcutaneous administration of the same neurotrophin had no effect, suggests that neurotrophin acts via uptake into the nerve terminal and transport back to the cell body. Such receptor-mediated transport is known to occur in sensory axons (DiStefano et al., 1992) and is accelerated after nerve injury (DiStefano and Curtis, 1994).

Although NT-3 promoted recovery of EPSP amplitude elicited by axotomized afferents, it failed to improve the ability of the synapses to withstand the effects of high-frequency stimulation, i.e., they remained prone to depression. This suggests that administration of single neurotrophins does not substitute entirely for the normal muscle because reinnervation of muscle led to complete recovery in EPSP amplitude and substantial recovery of EPSP amplitude modulation (Mendell et al., 1995). Axons reinnervating muscle did not necessarily resupply their original receptor type (Collins et al., 1986). However, even permitting these axons to reinnervate the skin resulted in a more complete recovery of synaptic properties, particularly EPSP amplitude modulation (Mendell et al., 1995), than was observed after neurotrophin treatment. It is not known what factors are present in muscle and skin that allow a more complete recovery of central synaptic properties than were observed in the present experiments. It remains to be seen whether neurotrophins either individually in different dosages or as a cocktail can substitute for the influence of the periphery in restoring the normal function of central neurons and their synapses.

Vehicle or subcutaneous treatment of axotomized afferents or motor axons over 4 weeks resulted in smaller EPSPs with more negative values of amplitude modulation than in intact controls (see also Mendell et al., 1995). This correlation is opposite to that observed in intact preparations in which smaller EPSPs exhibit more positive values of EPSP amplitude modulation (Collins et al., 1984, 1988; Mendell et al., 1995). In contrast, afferent axotomy (in rats) for $3 \mathrm{~d}$ rather than 4 weeks results in enlarged EPSPs that exhibit more negative modulation (Seburn and Cope, 1998), i.e., a coordinated change in these variables similar to that anticipated from the behavior of the intact system. Evidently, these synapses cannot withstand long-lasting axotomy without deregulation of the relationship between EPSP amplitude and amplitude modulation.

The mechanism by which NT-3 restores EPSP amplitude elicited by axotomized afferent fibers remains an open question. If NT-3 exerted its action by increasing probability of transmitter release, one would anticipate that they would become even more prone to depression during high-frequency stimulation than after control axotomy (Collins et al., 1984; Peshori et al., 1998). Because EPSP amplitude modulation did not undergo significant changes, alterations in transmitter release probability alone ap- 
pear not to account for the increased EPSP amplitude after neurotrophin treatment.

Another possible mechanism underlying restoration of EPSP amplitude by chronic neurotrophin treatment is that more terminals or more release sites in the existing terminals are formed, thereby increasing EPSP amplitude. This notion is supported by the finding that individual afferents elicited EPSPs in a greater proportion of heteronymous motoneurons than is observed in intact preparations. These new terminals could be equally prone to high-frequency depression as the ones already present, for example because of branch point blockade or less efficient recovery from transmitter depletion, thereby accounting for the negative values of EPSP amplitude modulation observed under these conditions. The correlation between recovery of EPSP amplitude produced by axotomized afferents and their conduction velocity (Fig. 5) suggests that the central changes in the terminals are related to those contributing to the restoration of axonal conduction velocity. Support for a structural basis for these changes is provided by the findings that neurofilament protein distribution (Gao et al., 1995) and cell body size (Helgren et al., 1997) recover after NT-3 treatment in models of neuropathy. However, the findings that conduction velocity, cell body size, and neurofilament protein recover to control values, whereas the EPSP amplitude reaches values substantially higher than control values suggest that additional factors contribute to these physiological findings. One such factor might be anterograde transport of NT-3, i.e., centrally from the group Ia dorsal root ganglion cells to their axon terminals in the ventral horn. Recent work by von Bartheld et al. (1996) showed that NT-3 injected into the eye of chick embryos was transported anterogradely to the optic tectum, where it appeared postsynaptically in dendrites and cell bodies. Precisely how the NT-3 might alter synaptic function remains to be determined; however, the fact that trkC mRNA is expressed in motoneurons (Johnson et al., 1996) suggests that NT-3 from some source is involved in normal motoneuron function.

The recovery induced by NT-3 appears to require a steady supply of this neurotrophin because afferent conduction velocity could be reduced substantially shortly after its removal. Mean EPSP amplitude was also reduced in an amount corresponding to the decrease in conduction velocity. The zero crossing ratio $5 \mathrm{~d}$ after removal of NT-3 was $0.8-0.9$, considerably lower than values $>0.9$ observed reliably 8 and $11 \mathrm{~d}$ after initial nerve transection. Recalling that the zero crossing ratio (i.e., conduction velocity of axotomized afferents) recovered completely by 4 weeks after NT-3 treatment, the decrease in conduction velocity after removal of NT-3 was more profound than that observed after the initial axotomy of the afferent fibers. This suggests that once the fibers are damaged, they are more vulnerable to the loss of the neurotrophin.

These results raise the question as to the normal role of peripherally derived NT-3 in maintenance of the integrity of Ia afferent fibers and their central connections. The finding that locally delivered NT-3 can increase the amplitude of EPSPs by the treated group Ia afferents well beyond normal values and that a steady supply of this neurotrophin is required indicates a possible role for NT-3 in regulating the strength of the monosynaptic stretch reflex under normal conditions. Additionally, we do not yet know whether elimination of NT-3 alone, i.e., without axotomy or treatments mimicking neuropathy, would lead to changes of the sort observed after these injuries. It will be important to determine whether removal of NT-3 in an otherwise intact preparation would lead to the changes noted after axotomy or in models of neuropathy. Does NT-3 play a physiological role in maintaining group Ia fibers and their connections, or is its action normally restricted to development with a possible therapeutic benefit after nerve injury because of its ability to increase diameter and central connectivity of damaged axons?

\section{REFERENCES}

Chao MV, Hempstead BL (1995) p75 and Trk: a two-receptor system. Trends Neurosci 18:321-326.

Collins III WF, Honig MG, Mendell LM (1984) Heterogeneity of group Ia synapses on homonymous a-motoneurons as revealed by high frequency stimulation of Ia afferent fibers. J Neurophysiol 52:980-993.

Collins III WF, Mendell LM, Munson JB (1986) On the specificity of sensory reinnervation of cat skeletal muscle. J Physiol (Lond) 375:587-609.

Collins III WF, Davis BM, Mendell LM (1988) Modulation of EPSP amplitude during high frequency stimulation depends on the correlation between potentiation, depression and facilitation. Brain Res 442:161-165.

Copray JC, Brouwer N (1994) A selective expression of neurotrophin-3 messenger RNA in muscle spindles of the rat. Neuroscience 63:1125-1135.

DiStefano PS, Curtis R (1994) Receptor mediated retrograde axonal transport of neurotrophic factors is increased after peripheral nerve injury. Prog Brain Res 103:35-42.

DiStefano PS, Friedman B, Radziejewski C, Alexander C, Boland P, Schick CM, Lindsay RM, Wiegand SJ (1992) The neurotrophins BDNF, NT-3, and NGF display distinct patterns of retrograde axonal transport in peripheral and central neurons. Neuron 8:983-993.

Friedman B, Kleinfeld D, Ip NY, Verge VMK, Moulton R, Boland P, Zlotchenko E, Lindsay RM, Liu L (1995) BDNF and NT-4/5 exert neurotrophic influences on injured adult spinal motor neurons. J Neurosci 15:1044-1056.

Gao W-Q, Dybdal N, Shinsky N, Murnane A, Schmelzer C, Siegel M, Keller G, Hefti F, Phillips HS, Winslow JW (1995) Neurotrophin-3 reverses experimental cisplatin-induced peripheral sensory neuropathy. Ann Neurol 38:30-37.

Goldring JM, Kuno M, Nunez R, Snider WD (1980) Reaction of synapses on motoneurones to section and restoration of peripheral sensory connexions in the cat. J Physiol (Lond) 309:185-198.

Helgren ME, Cliffer KD, Torrento K, Cavnor C, Curtis R, DiStefano PS, Wiegand SJ, Lindsay RM (1997) Neurotrophin-3 administration attenuates deficits of pyridoxine-induced large-fiber sensory neuropathy. J Neurosci 17:372-382.

Honig MG, Collins III WF, Mendell LM (1983) $\alpha$-Motoneurons EPSPs exhibit different frequency sensitivities to single Ia-afferent stimulation. J Neurophysiol 49:886-901.

Hory-Lee F, Russell M, Lindsay RM, Frank E (1993) Neurotrophin 3 supports the survival of developing muscle sensory neurons in culture. Proc Natl Acad Sci USA 90:2613-2617.

Johnson H, Hokfelt T, Ulfhake B (1996) Decreased expression of TrkB and TrkC mRNAs in spinal motoneurons of aged rats. Eur J Neurosci 8:494-499.

Johnson RD, Munson JB (1991) Regenerating sprouts of axotomized cat muscle afferents express characteristic firing patterns to mechanical stimulation. J Neurophysiol 66:2155-2158.

McMahon SB, Armanini MP, Ling LH, Phillips HS (1994) Expression and coexpression of Trk receptors in subpopulations of adult primary sensory neurons projecting to identified peripheral targets. Neuron 12:1161-1171.

Mendell LM, Henneman E (1971) Terminals on single Ia fibers: Location, density and distribution within a pool of 300 homonymous motoneurons. J Neurophysiol 34:171-187.

Mendell LM, Taylor JS, Johnson RD, Munson JB (1995) Rescue of motoneuron and muscle afferent function in cats by regeneration into skin. II. Ia-motoneuron synapse. J Neurophysiol 73:662-673.

Mendell LM, Johnson RD, Munson JB (1996) Local application of NT- $4 / 5$ to the proximal cut end of a nerve limits the development of full-blown axotomy response. Soc Neurosci Abstr 22:992.

Mendell LM, Johnson RD, Munson JB (1998) Properties of individual NT-3 treated axotomized muscle afferents and their spinal projections. Soc Neurosci Abstr 24:801.

Munson JB, Sypert GW (1979a) Properties of single central Ia afferent fibres projecting to motoneurones. J Physiol (Lond) 296:315-327. 
Munson JB, Sypert GW (1979b) Properties of single excitatory postsynaptic potentials in triceps surae motoneurons. J Physiol (Lond) 296:329-342.

Munson JB, Johnson RD, Mendell LM (1997a) NT-3 increases amplitude of EPSPs produced by axotomized group Ia afferents. J Neurophysiol 77:2209-2212.

Munson JB, Johnson RD, Mendell LM (1997b) Time course of NT-3 action on axotomized muscle afferents in adult cats. Soc Neurosci Abstr 23:887.

Munson JB, Shelton DL, McMahon SB (1997c) Adult mammalian sensory and motor neurones: roles of endogenous neurotrophins and rescue by exogenous neurotrophins following axotomy. J Neurosci 17:470-476.

Peshori KR, Collins WF, Mendell LM (1998) EPSP amplitude modulation at the rat Ia-alpha motoneuron synapse: effects of $\mathrm{GABA}_{\mathrm{B}}$ receptor agonists and antagonists. J Neurophysiol 79:181-189.

Schmalbruch H, Rosenthal A (1995) Neurotrophin-4/5 postpones the death of injured spinal motoneurons in newborn rats. Brain Res 700:254-260.

Scott JG, Mendell LM (1976) Individual EPSPs produced by single triceps surae Ia afferent fibers in homonymous and heteronymous motoneurons. J Neurophysiol 39:679-692.

Seburn KL, Cope TC (1998) Short-term afferent axotomy increases both strength and depression at Ia-Motoneuron synapses in rat. J Neurosci 18:1142-1147.

Sendtner M, Holtmann B, Kolbeck R, Thoenen H, Barde Y-A (1992) Brain-derived neurotrophic factor prevents the death of motor neurons in newborn rats after nerve section. Nature 360:757-759.

Snider WD, Silos-Santiago I (1996) Dorsal root ganglion neurons require functional neurotrophin receptors for survival during development. Philos Trans R Soc Lond B Biol Sci 351:395-403.

Titmus MJ, Faber DF (1990) Axotomy-induced alterations in the electrophysiological characteristics of neurons. Prog Neurobiol 35:1-51.

Von Bartheld CS, Byers MR, Williams R, Bothwell M (1996) Anterograde transport of neurotrophins and axodendritic transfer in the developing visual system. Nature 379:830-833.

Wright DE, Zhou L, Kucera J, Snider WD (1997) Introduction of a neurotrophin-3 transgene into muscle selectively rescues proprioceptive neurons in mice lacking endogenous neurotrophin-3. Neuron 19:503-517.

Yan Q, Elliott J, Snider WD (1992) Brain-derived neurotrophic factor rescues spinal motor neurons from axotomy-induced cell death. Nature 360:753-755.

Zengel JE, Reid SA, Sypert GW, Munson JB (1985) Membrane electri$\mathrm{cal}$ properties and prediction of motor-unit type of medial gastrocnemius motoneurons in the cat. J Neurophysiol 53:1323-1344. 